\title{
O uso de aplicativos de leitura e escrita com alunos com deficiência intelectual
}

\author{
The use of reading and writing applications with students with intellectual \\ disabilities
}

\author{
El uso de aplicaciones de lectura y escritura con estudiantes con \\ discapacidad intelectual
}

\begin{abstract}
Ana Cláudia Oliveira Pavão
Professora doutora na Universidade Federal de Santa Maria, Santa Maria, Rio Grande do Sul, Brasil. anaclaudiaoliveira.pavao@gmail.com

ORCID - http://orcid.org/0000-0002-9914-3700
\end{abstract}

\section{Karolina Waechter Simon}

Mestra pela Universidade Federal de Santa Maria, Santa Maria, Rio Grande do Sul, Brasil.

karolinasimon@gmail.com

ORCID - https://orcid.org/0000-0001-5425-4987

Recebido em 4 junho 2020

Aprovado em 3 de setembro de 2020

Publicado em 26 de outubro de 2020

\section{RESUMO}

O estudo objetiva analisar o potencial dos aplicativos educacionais no ensino da leitura e escrita a estudantes com deficiência intelectual. Para tal, apresenta abordagem qualitativa e procedimentos de pesquisa participante. Os sujeitos são 12 estudantes com deficiência intelectual. $\mathrm{O}$ instrumento foi o diário de campo, por meio de uma matriz de referência, que caracteriza quatro níveis de leitura e escrita e requisitos pedagógicos e técnicos que os aplicativos devem conter em cada nível. Foram analisados doze aplicativos e os dados tratados por uma análise reflexiva. Os resultados evidenciam que os aplicativos não são desenvolvidos considerando o nível de leitura e escrita; nem todo aplicativo é adequado para o ensino e aprendizagem, mesmo possuindo requisitos importantes e, por fim, concluise a necessidade de desenvolver diretrizes para a utilização de aplicativos que contemplem os quatro níveis de leitura e escrita.

Palavras-chave: Aplicativos; níveis de leitura e escrita; deficiência intelectual.

\section{ABSTRACT}

This study aims to analyse the educational applicatives' potential in reading and writing tuition of students with intellectual disabilities. It is used a qualitative research, with exploratory goals and participant research procedures. The subjects are twelve students with intellectual disabilities. The instrument was a field diary through a reference matrix which characterises four levels of reading and writing, pedagogical and technical requirements that the applicatives are supposed to contain in each level. Twelve applicatives were analysed and the data was treated through a reflexive analysis. The results point that the applicatives are not developed considering the reading and writing levels and the subject with intellectual disabilities; not all applicative is adequate for teaching and learning even though it attends important requirements; and, lastly, it is 
concluded that is necessary to develop guidelines for the creation and usage of applicatives that embrace the four reading and writing levels.

Keywords: Applicatives; reading and writing levels; intellectual disabilities.

\section{RESUMEN}

El estudio objetiva analisar el potencial de las aplicaciones educativas en la enseñanza de lectura y escritura a estudientes con deficiencia intelectual. Con este fin, presenta un abordaje cualitativa y procedimientos de investigación participativos. Los sujetos son doce estudientes con deficiencia intelectual. El instrumento analisado fue el diario de campo, a través de una matriz de referencia, que presenta cuatro niveles de lectura y escritura, bién como requisitos pedagógicos y técnicos que las aplicaciones deben contener en cada nivel. Se analizaron doce aplicaciones y los datos se trataron mediante un análisis reflexivo. Los resultados muestran que las aplicaciones no se han desarrollado teniendo en cuenta el nivel de lectura y escritura; no todas las aplicaciones son adecuadas para la enseñanza y el aprendizaje, a pesar de que tienen requisitos importantes y, además, se concluye que es necesario desarrollar directrices para el uso de aplicaciones que contemplen los cuatro niveles de lectura y escritura.

Palabras clave: Aplicaciones; niveles de lectura y escritura; deficiencia intelectual.

\section{Introdução}

O paradigma da inclusão vem instaurando-se mundialmente há algumas décadas, recebendo força a partir da década de 90, com a realização de conferências mundiais e, principalmente, com a publicação da Declaração de Salamanca, sendo um marco no movimento da inclusão social (BRASIL, 1994).

No Brasil, percebe-se o fortalecimento das políticas e práticas de inclusão escolar, incentivadas principalmente pela Política Nacional de Educação Especial na Perspectiva da Educação Inclusiva (PNEE/PEI), que tem como finalidade o acesso, a participação e a aprendizagem dos alunos com deficiência, transtornos globais do desenvolvimento e altas habilidades/superdotação nas escolas regulares (BRASIL, 2008).

Concomitante com os progressos na educação de pessoas com deficiência, também vem ocorrendo avanços no uso das tecnologias da informação e comunicação-TIC, como meio de ensino/aprendizagem, sobretudo, com o uso de tecnologias móveis e disponibilização de aplicativos gratuitos em todas as áreas do conhecimento. Segundo a Organização das Nações Unidas para a Educação, a Ciência e a Cultura- UNESCO (2014, p. 7), "Estudos apontam que as tecnologias móveis podem ampliar e enriquecer oportunidades educacionais para estudantes de diversos ambientes". Consequentemente, os aplicativos podem melhorar as práticas pedagógicas, introduzindo novas vias de aprendizagem. 
Assim, o uso de aplicativos educacionais é uma das formas que as tecnologias têm chegado à sala de aula regular e ao atendimento educacional especializado - AEE. Estudos de Passerino, Dias e Rapkiewicz (2010); Henrique, Souza \& Silva (2010); Espinosa e Gómez (2016); Tobias, Fletcher e Wind (2014); Bahia (2016); Petry (2016); Busarello (2016); Galvão Filho (2016), Santos (2014), Rodrigues (2018), Paixão (2018), UNESCO (2014), entre outros, apontam os benefícios que as TIC, dentre as quais inserem-se os aplicativos, possibilitam aos estudantes, como recursos que estimulam, motivam e desenvolvem aspectos necessários à aprendizagem.

Galvão Filho (2012) aponta que os avanços tecnológicos trazem novas alternativas e concepções, as quais buscam organizar e disponibilizar estratégias pedagógicas e tecnologias educacionais diferentes que, levam em consideração as especificidades de cada um e que, assim, possam dar conta das necessidades cognitivas de todos os sujeitos, com ou sem deficiência. Essa assertiva é corroborada pelo documento da UNESCO, o qual afirma que "os educadores podem, por exemplo, escolher entre vários aplicativos customizados para atender às necessidades de cada aluno, empoderando assim a aprendizagem personalizada, que deverá caracterizar a educação formal no futuro" (UNESCO 2014, p. 23).

Segundo Fagundes (2019), tendo em vista a rapidez no avanço das tecnologias e sua influência na vida das pessoas, percebe-se a importância de atualizar e buscar conhecimentos sobre estes novos recursos. A disponibilidade crescente dos aplicativos necessita a reflexão e a análise do potencial dessa tecnologia com o público do AEE. Tratando-se da aprendizagem do estudante com deficiência intelectual, as habilidades de leitura e escrita são um dos objetivos propostos no AEE e os aplicativos educacionais têm sido um dos meios pedagógicos utilizados no desenvolvimento dessas habilidades, visto que proporcionam uma aprendizagem individualizada, por meio de recursos lúdicos e motivadores que, geralmente, fazem parte do cotidiano.

No entanto, o que se tem visto é uma dificuldade em encontrar aplicativos que contenham requisitos técnicos e pedagógicos necessários para desenvolver essas habilidades e que sejam adequados ao nível de leitura e escrita, em que os estudantes encontram-se. Para Ferreiro e Teberosky (1986), as crianças evoluem no processo de leitura e escrita, interagindo com a língua escrita, criando hipóteses e compreendendo o que está sendo lido e não apenas decodificando as letras. As autoras ainda apontam que 
a leitura e a escrita passam por quatro níveis, durante o período de alfabetização: nível présilábico, nível silábico, nível silábico-alfabético e nível alfabético.

Quanto aos estudantes com deficiência intelectual, os processos de aprendizagem da leitura e escrita são semelhantes aos daqueles sem deficiência sob muitos aspectos, pois transcorrem pelos mesmos níveis de alfabetização e constroem hipóteses acerca do objeto escrito. No entanto, os estudantes com deficiência intelectual podem apresentar um ritmo mais lento na evolução destes níveis e necessitar da intervenção de um par mais experiente neste processo de apropriação. A dificuldade e particularidade dos estudantes com deficiência intelectual é a dificuldade cognitiva que enfrentam para o aprendizado, as quais dependem do grau, intensidade, história de vida e estimulação de cada indivíduo (MANTOAN e BATISTA, 2007).

Nessa perspectiva, segundo Rocha e Thiengo (2019), a alfabetização de estudantes com deficiência intelectual é potencializada a partir da utilização de estratégias, em que o estudante tenha participação ativa e que possibilitem a verificação e aprimoramento de habilidades e o desenvolvimento de novos conhecimentos. Dentre as possibilidades, os autores apontam os recursos tecnológicos. Desse modo, entende-se que a utilização de aplicativos de leitura e escrita contempla sobremaneira essa questão.

Partindo das premissas anteriores, destaca-se a importância da utilização de aplicativos apropriados nos processos de construção da leitura e escrita destes estudantes, no sentido de estimular conflitos e desafios cognitivos, utilizando recursos tecnológicos adequados a cada um dos quatro níveis de leitura e de escrita propostos por Ferreiro e Teberosky (1986). Diante disso, este estudo tem como objetivo analisar o potencial dos aplicativos educacionais no ensino da leitura e escrita dos estudantes com deficiência intelectual. Para tal, foi utilizada uma Matriz de Referência, a qual além de contemplar os requisitos necessários que o estudante deve apresentar em cada nível de leitura e escrita, aponta quais aspectos pedagógicos e técnicos os aplicativos devem conter em cada um desses níveis.

\section{Método}

Esta é uma pesquisa de abordagem qualitativa, pois "aprofunda-se no mundo dos significados das ações e relações humanas, um lado não perceptível e não captável em equações médias e estatísticas" (MINAYO 2014, p. 22). Em relação aos objetivos, esta pesquisa classifica-se como exploratória, visto que procura buscar um maior conhecimento 
http://dx.doi.org/10.5902/1984686X46925

do tema escolhido, proporcionando maior simplificação e, assim, tornando-o o mais objetivo possível. Configura-se, ainda, como uma pesquisa participante, no que se refere ao procedimento metodológico. Segundo Gil (1991), a pesquisa participante, assim como a pesquisa ação, caracteriza-se pela interação entre pesquisadores e membros das situações investigadas Assim, este estudo parte da realidade da população envolvida, em busca de uma solução para o problema pesquisado e tem a participação ativa do pesquisador.

Desse modo, participaram deste estudo doze estudantes com deficiência intelectual, que frequentavam o Atendimento Educacional Especializado-AEE, em uma Escola Municipal, no Rio Grande do Sul, matriculados entre o $1^{\circ}$ e 8ํano do Ensino Fundamental, e que possuíam idades entre sete e quinze anos. O critério de escolha dos sujeitos foi devido aos seus planos de atendimento individualizado terem como objetivo principal 0 desenvolvimento da leitura e escrita.

O instrumento de coleta de dados foi o diário de campo, por meio de observação participante, no qual foram feitos registros da análise dos 12 aplicativos selecionados, sendo utilizada uma Matriz de referência, que apontava aspectos técnicos e pedagógicos necessários aos aplicativos para atender aos níveis de leitura e escrita.

As etapas do estudo constituíram-se na escolha dos aplicativos que seriam utilizados, na seleção dos alunos participantes do estudo, utilização dos aplicativos e observação dos alunos durante a utilização destes e a na análise dos dados observados.

Portanto, foram utilizados três aplicativos com três alunos de cada nível de leitura e escrita, totalizando 12 acompanhamentos, os quais ocorreram individualmente, ou seja, para cada sujeito participante foi realizado o registro das observações, conforme matriz de referência, observando-se os quatro níveis de leitura e de escrita. Diante disso, a análise dos resultados desta investigação consistiu em uma análise reflexiva, a qual, segundo Andrade (2006), configura-se nas relações entre as ideias do autor em razão do contexto científico e filosófico de diferentes épocas; na análise crítica ou avaliação; discussão e no julgamento do conteúdo do texto (ANDRADE, 2006). Este estudo seguiu as normas para pesquisa com seres humanos, sendo aprovado pelo Comitê de Ética, com o parecer nํㅜ 3.805.495.

\section{Matriz de Referência}

A Matriz de Referência - Figura 1- tem como base os estudos de Ferreiro e Teberosky (1986), com o objetivo de apresentar os requisitos necessários que indicam em que nível de leitura e escrita o estudante encontra-se e de traçar parâmetros que indicam aspectos 
http://dx.doi.org/10.5902/1984686X46925

pedagógicos e técnicos, os quais devem ser contemplados pelos aplicativos, considerando cada nível. Para além desses objetivos, a Matriz de Referência foi utilizada como um instrumento de suporte ao diário de campo, na observação participante desse estudo. Desse modo, a matriz de referência serviu para verificar quais os aspectos técnicos e pedagógicos necessários para cada nível de leitura e escrita estavam presentes nos aplicativos utilizados.

Portanto, na primeira coluna, foram expostos os níveis apresentados por Ferreiro e Teberosky (1986) e, na coluna ao lado, foram descritos os principais requisitos de cada um destes níveis. A terceira e quarta colunas da Matriz foram compostas com base nos estudos realizados, a partir da teoria das autoras Ferreiro e Teberosky (1986).

Figura 1- Matriz de Referência

\begin{tabular}{|c|c|c|c|}
\hline $\begin{array}{l}\text { NIVEIS DE } \\
\text { LEITURA E } \\
\text { ESCRITA }\end{array}$ & REQUISITOS & ASPECTOS PEDAGOGICOS & ASPECTOS TECNICOS \\
\hline PRE-SILABICO & $\begin{array}{l}\text { - letra e desenho tem um } \\
\text { mesmo significado; } \\
\text { - nâo diferencia letra e } \\
\text { numero; } \\
\text { - Utiliza desenhos e rabiscos. }\end{array}$ & $\begin{array}{l}\text { - enunciados claros e objetivos } \\
\text { - associaçâo de imagens a } \\
\text { imagens com escrita } \\
\text { - separar elou marcar as letras } \\
\text { ou os numeros } \\
\text { - imagem com a escrita do } \\
\text { nome e associação a letra } \\
\text { inicial } \\
\text { - ordem alfabética } \\
\text { - motivaçäo } \\
\text { - parear nomes ou desenhos ou } \\
\text { letras iguais. } \\
\text { - ludicidade }\end{array}$ & $\begin{array}{l}\text {-imagens e recursos } \\
\text { visuais } \\
\text { - enunciados em ảudio } \\
\text { - letra bastâo } \\
\text { - feedback }\end{array}$ \\
\hline SILABICO & $\begin{array}{l}\text { - ja supóem que a escrita } \\
\text { representa a fala; } \\
\text { - ao fazer a leitura aponta } \\
\text { uma letra para cada fonema. }\end{array}$ & $\begin{array}{l}\text { - associar sons inicial final a } \\
\text { imagem; } \\
\text { - completar com as vogais das } \\
\text { palavras; } \\
\text { - rimas } \\
\text { - associar palavra a imagem; } \\
\text { - ludicidade e motivaçâo } \\
\text { - separação de silabas; } \\
\text { - completar com silabas; }\end{array}$ & $\begin{array}{l}\text { - enunciados em áudio } \\
\text { - audio com sons } \\
\text { pausados e claros } \\
\text { (pronuncia bem frisada) } \\
\text { - letra bastão } \\
\text { - feedback }\end{array}$ \\
\hline $\begin{array}{l}\text { SILABICO- } \\
\text { ALFABETICO }\end{array}$ & $\begin{array}{l}\text { - ora escreve uma letra para } \\
\text { cada silaba, ora escreve } \\
\text { silaba completa; } \\
\text {-percebe a necessidade de } \\
\text { mais que uma letra para } \\
\text { representar a silaba; } \\
\text { - dificuldade nas silabas } \\
\text { complexas. }\end{array}$ & $\begin{array}{l}\text { - completar textos com } \\
\text { palavras } \\
\text { - completar palavras com } \\
\text { sílabas complexas } \\
\text { - contar o numero de gillabas e } \\
\text { de letras } \\
\text { - ludicidade e motivaçâo } \\
\text { - ordenar sillabas }\end{array}$ & $\begin{array}{l}\text { - letra bastão } \\
\text { - enunciados em áudio e } \\
\text { escrito } \\
\text { - feedback }\end{array}$ \\
\hline ALFABETICO & $\begin{array}{l}\text { - reconhece o valor sonoro } \\
\text { de quase ou todas as letras } \\
\text { do alfabeto; } \\
\text { - compreende o sistema de } \\
\text { escrita alfabético. }\end{array}$ & $\begin{array}{l}\text { - leituras diversas } \\
\text { - ludicidade e motivaçẫo } \\
\text { - localizaçâo de palavras ou } \\
\text { frases; } \\
\text { - ordenar textos; }\end{array}$ & $\begin{array}{l}\text { - letra bastão, imprensa } \\
\text { ou cursiva } \\
\text { - enunciados escritos } \\
\text { - feedback }\end{array}$ \\
\hline
\end{tabular}

Fonte: elaborado pelas autoras (2018), baseado em Ferreiro e Teberosky (1986). 
http://dx.doi.org/10.5902/1984686X46925

Sendo assim, a Matriz de Referência é composta por quatro níveis de leitura e de escrita, sendo o primeiro o pré-silábico, no qual os requisitos são a utilização de desenhos e de rabiscos, diferenciação de letras e de números e letras e desenhos com o mesmo significado. Entende-se por aspectos pedagógicos, para este nível, a associação das imagens com a escrita, a utilização de enunciados claros e objetivos e, por aspectos técnicos, a utilização de recursos visuais e enunciados em áudio.

No segundo nível, o silábico, o requisito é, principalmente, a utilização de uma letra para cada fonema. Diante disso, os aspectos pedagógicos consistem no uso de rimas, na associação de sons com as sílabas, entre outros. Já, nos aspectos técnicos, está a presença de áudios com sons bem frisados e claros.

Para o nível silábico-alfabético, o requisito central é a escrita com uma letra para cada sílaba e a escrita com a sílaba completa. Como aspectos pedagógicos, estão a organização de sílabas para a formação das palavras e a contagem do número de sílabas e letras. Nos aspectos técnicos, estão a utilização da letra bastão e os enunciados em áudios e escritos.

E, no último nível, o alfabético, há o reconhecimento do valor sonoro de quase todas as letras do alfabeto como característica. Quanto aos aspectos pedagógicos, destacam-se leituras diversas, localização de palavras e frases e organização de textos. E, nos aspectos técnicos, os enunciados escritos e a utilização de outras letras, não somente a bastão.

\section{Discussão dos resultados}

\section{Caracterização dos sujeitos}

Os sujeitos desta pesquisa são doze estudantes atendidos pelo AEE, dos quais três são do sexo feminino e nove do sexo masculino. As idades variaram entre sete e quinze anos e os participantes frequentam do $1^{\circ}$ ao $8^{\circ}$ ano do Ensino Fundamental. Todos apresentam diagnóstico de DI e três têm associados ausência de estimulação, dois têm transtorno do déficit de atenção e hiperatividade e um tem dificuldade em expressar-se verbalmente. Assim, os estudantes foram identificados pela letra " $A$ ", seguido dos numerais do 1 ao 12, de tal modo que seja preservado o anonimato de cada um deles.

Os participantes frequentam o AEE duas vezes por semana e cada atendimento tem duração de aproximadamente quarenta e cinco minutos. A escolha desses estudantes foi baseada no plano de atendimento individualizado ter como intuito central o aprimoramento das habilidades de leitura e escrita. 
http://dx.doi.org/10.5902/1984686X46925

A classificação do nível de leitura e de escrita de cada estudante deu-se a partir da aplicação do ditado balanceado (MOOJEN, 2009). Este ditado consiste em um instrumento de avaliação para verificar a frequência de erros de conversor fonema-grafema, regras contextuais e regras arbitrárias, estabelecendo média e desvio padrão da turma testada.

Desse modo, foi possível constatar que $A 1, A 2$ e A3 encontram-se no nível présilábico; $A 4, A 5$ e A6 encontram-se no nível silábico; $A 7, A 8$ e $A 9$ encontram-se no nível silábico-alfabético e, no último nível, o alfabético, encontram-se os estudantes $A 10, A 11$ e A12.

\section{Análise dos aplicativos}

Para este estudo, foram selecionados doze aplicativos, três para cada nível de leitura e de escrita, tendo como critério de escolha uma análise prévia daqueles que contemplavam, de algum modo, a Matriz de Referência.

\section{Nível pré-silábico}

Os aplicativos selecionados para o nível pré-silábico foram o $A B C$ for Kids, Learning letter e Alphabet, todos com opção em língua portuguesa. $O A B C$ for Kids é um jogo educativo com uma forma divertida e lúdica de trabalhar o alfabeto e as letras. No Learning letter, é possível aprender a reconhecer as letras do alfabeto pelo nome e pela grafia. E o Alphabet é um aplicativo que possibilita aprender os sons das vogais e das consoantes e descobrir os traçados das letras e palavras que começam com cada letra.

$\mathrm{O}$ aplicativo $A B C$ for Kids tem um áudio inicial convidativo, que instigou os três estudantes a utilizá-lo, relatando ser um jogo bem divertido, demonstrando assim, que o aplicativo é bastante lúdico para a utilização com crianças. A ludicidade é um fato de suma importância, uma vez que permitiu que os sujeitos participassem e aprendessem diferentes habilidades, brincando, de uma forma prazerosa. Busarello (2016, p. 31) faz referência a esse aspecto, "o ato de jogar, além de proporcionar prazer, é um meio de o sujeito desenvolver habilidades, estimulando atenção e memória”.

$O A B C$ for Kids possui a presença de feedback positivo (palmas) e negativo (áudio com reforço para tentar novamente). Este requisito é importante para qualquer aplicativo utilizado com o intuito de promover a aprendizagem, visto que proporciona aos estudantes compreender quando estavam corretos ou não. Além disso, os feedbacks proporcionam 
http://dx.doi.org/10.5902/1984686X46925

uma aprendizagem, por meio do erro construtivo, pois foi possível observar que, quando os estudantes erravam, esse erro virou um aprendizado e a nova tentativa foi divertida.

O aplicativo tem três opções de jogos, a primeira tem como intuito ampliar o conhecimento do alfabeto, assim, as letras são apresentadas juntamente com uma palavra que inicia com esta letra e a respectiva imagem que inicia com esta letra. Para Ferreiro e Teberosky (1986), no nível pré-silábico, as letras ainda não têm significado, pois os estudantes utilizam desenhos, rabiscos ou garatujas para representar a escrita solicitada. Em razão disto, considera-se que esta opção do aplicativo está de acordo com os aspectos pedagógicos deste nível. Os estudantes demonstraram entusiasmo pelas imagens e isto deve-se ao desconhecimento de algumas imagens, por serem distantes dos seus contextos, fazendo-os aprender além do que se pretendia.

Henrique, Souza e Silva (2010, p. 63) ratificam essa afirmativa: "A singularidade das situações de ensino dos próprios autores envolvidos, dos objetivos traçados e da especificidade do objeto de conhecimento, além é claro do próprio material, são determinantes para o sucesso ou insucesso escolar". Outro ponto relevante desta opção foi a letra inicial do nome destacada de cor diferente e em letra de imprensa. A presença de outros tipos de letras, diferentes da letra bastão, gerou confusões na compreensão, pois estes estudantes encontram-se em fase de apropriação dessas habilidades, tendo reconhecido somente as letras iniciais de seus nomes. Apenas dois estudantes questionaram que letras eram as demais.

A segunda opção é um jogo da memória das letras, com três níveis de dificuldades. Segundo Busarello (2016, p.108), essas etapas "podem ser utilizadas como forma de controle de aumento do crescimento dos níveis de habilidade e de conhecimento do indivíduo no sistema". O enunciado desse aplicativo é em áudio e possui feedback positivo e negativo. Nesta opção de jogo, que já era conhecido, pois os estudantes utilizavam atividades semelhantes, visto que demonstraram uma boa desenvoltura, não apresentando dificuldade em realizar e reconhecer as letras, pois todas eram em formato bastão.

$\mathrm{Na}$ outra opção de jogo, o objetivo consistia em encontrar a letra igual a solicitada. Esta foi a que os sujeitos mais gostaram e divertiram-se, pois é bastante lúdica e o layout é atrativo. Em relação à motivação apresentada pelos estudantes, Petry (2016) afirma que videogames e jogos de computador com outros sistemas educacionais trazem evidências das qualidades motivacionais dos jogos digitais. 
http://dx.doi.org/10.5902/1984686X46925

Desse modo, pode-se inferir que o aplicativo $A B C$ for Kids apresenta requisitos que contemplam este nível de leitura e escrita. Sendo assim, considera-se este aplicativo adequado para o aprimoramento das habilidades de leitura e escrita deste nível.

No segundo aplicativo para esse nível de leitura e de escrita, Learning letter, também é possível escolher três opções de jogo. Isto disponibiliza uma variedade de caminhos para os sujeitos, o que, segundo Busarello (2016, p.120), "permite que o aluno possa acompanhar a sequência de tarefas que melhor lhe convir, criando um caminho próprio de interação". A primeira é para os usuários combinarem as letras com iguais. Os participantes não tiveram dificuldade, apesar de não ter nenhum enunciado escrito e em áudio. No entanto, ao aparecer cada letra para encaixar, havia o áudio com o nome desta letra, que estava em formato bastão, o que favorecia a compreensão e a aprendizagem dos três estudantes, já que conseguiam associar estas aos seus respectivos nomes.

A segunda opção, que consistia em compor os nomes dos desenhos, encaixando as letras que formavam seus nomes, trouxe algumas dificuldades para os estudantes, pois as palavras eram todos nomes de frutas e alguns eram desconhecidos. A outra opção do aplicativo consistia em que os estudantes pegassem todas as letras corretas, conforme a letra que era solicitada. Esta opção instigou os três estudantes, pois era um jogo competitivo, de modo que eles tinham que achar a letra e clicar antes que ela desaparecesse. Segundo Busarello (2016, p.19), "o nível de engajamento do sujeito é influenciado pelo grau de dedicação do mesmo às tarefas designadas".

Observou-se que nenhuma das três opções possui feedback positivo e negativo, 0 que fez com que os estudantes não compreendessem se estavam corretos ou não. Esse retorno para os estudantes é de suma importância para o processo de aprendizagem. Conforme Busarello (2016, p.98), essa "liberdade em fracassar nas atividades permite aos sujeitos aumentar seu envolvimento através da experimentação sem medo". Ademais, o aplicativo não possui instruções e enunciados em áudio e escrito, por isso foi necessária mediação para os três estudantes compreenderem o que deveria ser realizado. Desse modo, pode-se inferir que o aplicativo Learning letter não é totalmente adequado para estudantes no nível pré-silábico, pois não possui áudio com as instruções dos jogos e também não há nenhum tipo de feedback.

O terceiro aplicativo, Alphabet, possui quatro opções de jogo, a primeira consiste em conhecer as letras e imagens que iniciam com estas letras. Nesta opção, há áudio com instruções, recursos visuais atrativos e a possibilidade de escutar o nome das imagens 
diversas vezes. Esta opção possui somente três imagens para cada letra e possui a letra inicial em bastão e de imprensa, o que proporcionou aos estudantes o conhecimento que existem vários tipos de formas para escrevermos a letra " $A$ ", por exemplo.

Na segunda opção, o objetivo é ligar as letras ao encaixe correto, a qual foi de fácil compreensão para os três estudantes, visto que há uma instrução em áudio. A única dificuldade observada foi o reconhecimento de algumas letras que não estavam em formato bastão, mas imprensa. Paixão (2018) recomenda que os aplicativos devem contemplar figuras de fácil compreensão e a inclusão da letra bastão, pois esses recursos possibilitam diminuir a barreira muitas vezes apresentada pela deficiência. $O$ estudante $A 3$ não teve essa dificuldade, pois realizou a ligação com a primeira opção de jogo deste aplicativo, o qual traz os dois tipos de letras juntas. Nesta opção de jogo, existe o feedback positivo, mas não possui o negativo. Quando há o erro, simplesmente o jogo não avança. Espinosa e Gómez (2016, p.68) afirmam que "os diferentes tipos de feedback enviados aos alunos através dos jogos podem chegar a afetar de maneira significativa o processo de aprendizagem".

$\mathrm{Na}$ outra opção, os estudantes deveriam escolher a imagem que iniciava com a letra solicitada. Nesta opção, nenhum dos estudantes teve dificuldade de compreender como realizar, pois havia um enunciado em áudio claro e objetivo. Para Santos (2014), o uso de imagens apelativas e coloridas e os efeitos sonoros ligados às respostas corretas ou erradas servem de estímulo para a motivação e melhoram a atenção e concentração nas atividades desenvolvidas. Nesta opção há feedback positivo e negativo, proporcionando a reflexão dos estudantes. Sobre isto, Busarello (2016) destaca a importância desses ambientes promoverem a diversidade de caminhos de aprendizagem e os sistemas de decisão e de recompensa por parte dos estudantes. Então, conclui-se que o aplicativo Alphabet, apesar de não apresentar feedback, é adequado para sujeitos no nível présilábico, visto que proporciona ao estudante reconhecer diferentes tipos de letras e associar estas a imagens que iniciam com determinadas letras.

Portanto, para o primeiro nível de leitura e escrita os aplicativos $A B C$ for Kids, e Alphabet são mais adequados. $O$ aplicativo Learning letter possui somente os requisitos de letra bastão e pareamento de imagens ou desenhos ou letras iguais, considerados adequados para este nível, necessitando de mediação constante para a utilização com estudantes neste nível. 
http://dx.doi.org/10.5902/1984686X46925

\section{Nível silábico}

Para o segundo nível, o silábico, os aplicativos escolhidos foram Alfabetizando, Lele das sílabas e Forma palavras. Diante disso, os estudantes não tiveram dificuldade em compreender o que era proposto no aplicativo Alfabetizando, mesmo não contendo nenhuma instrução em áudio ou enunciado explicativo. Além disso, não possui nenhum áudio com os sons das letras ou nome das imagens. O aplicativo não possui feedback negativo, somente é concluída a etapa, quando são escolhidas as letras corretas das palavras, após isto há um feedback positivo com um recurso visual.

Busarello (2016) ressalta a importância destes feedbacks negativos, pois auxiliam os indivíduos na construção e no melhoramento de suas estratégias. Esta foi uma dificuldade apresentada pelos estudantes, pois algumas imagens eles desconheciam o nome e não podiam pronunciar para perceberem que letras deveriam utilizar. O fato de não apresentar feedback acentuou a dificuldade apresentada pelos alunos, consequentemente, o aplicativo não respondeu à resolução do problema que se propunha. Henrique, Souza e Silva (2010, p.62), sobre os aplicativos, afirmam "que mesmo que sejam classificados como de qualidade, sempre terão seus limites, pois a eficiência e eficácia dependem do contexto". Desse modo, pode-se concluir que o aplicativo Alfabetizando não é adequado para o nível silábico, pois não apresenta características importantes para esse nível de leitura e escrita, como a presença de áudio com os sons das letras e nome das imagens.

No Lele das Sílabas, inicialmente, todos tiveram dificuldade de perceber como realizar a proposta, pois não possui nenhuma orientação ou instrução de jogo. Para que os três estudantes manuseassem o aplicativo, foi necessária mediação, como leitura com o aluno e explicação mais detalhada. Esse aspecto é destacado por Busarello (2016, p. 120), o qual afirma que, "quando as tarefas são adaptadas ao nível de habilidade de cada sujeito, aumenta-se a expectativa desses completarem com êxito a tarefa".

Os estudantes logo perceberam que, quando clicavam nas opções de sílabas para formar as palavras, era emitido o som de cada uma. Reconhecer que as letras representam os sons da fala é uma das características dos sujeitos neste nível, conforme Ferreiro e Teberosky (1986). Além disso, o aplicativo possui uma gama de palavras com nível de dificuldade progressiva e palavras simples conhecidas pelos três estudantes, o que favoreceu o desempenho na formação das palavras. Porém, o aplicativo não possui feedback positivo, mas quando a palavra está incorreta é dado um aviso sonoro e são retiradas todas as sílabas que tinham sido utilizadas. Este aspecto gerou confusão, pois 
todas as sílabas que haviam utilizado estavam incorretas. Segundo Busarello (2016, p. 51), é essencial que o "ambiente promova a diversidade de caminhos de aprendizagem e os sistemas de decisão e recompensa por parte dos sujeitos".

Apesar de o aplicativo Lele das Sílabas não contemplar alguns aspectos pedagógicos e técnicos e necessitar de mediação do professor em alguns momentos, considera-se parcialmente adequado a este nível de leitura e escrita, pois apresenta uma proposta pedagógica atrativa e adequada para o nível silábico.

O terceiro aplicativo, o Forma Palavras, não possui enunciado em áudio, somente instruções na forma escrita. Em razão disso, os três estudantes necessitaram de mediação para iniciar a tarefa. Além disso, o jogo não possui nenhum áudio com o nome das imagens que deve ser realizada a escrita e também não há os sons das letras ou sílabas formadas. Para Tobias, Fletcher e Wind (2014), os jogos mais efetivos para o processo de ensinoaprendizagem seriam aqueles cujas tarefas exigidas para sua execução demandassem o mesmo tipo de processo cognitivo que as tarefas desejadas externas ao jogo. Galvão Filho (2016, p. 317) reforça esta tese ao dizer que quando um aplicativo possui áudio, "na medida em que faz a leitura oral de todo texto que se encontra em formato digital, compensaria a "barreira" ou "impedimento" do acesso ao texto escrito por um aluno com deficiência intelectual que ainda não aprendeu a ler".

Um aspecto interessante deste aplicativo e que proporciona uma aprendizagem significativa é que, quando há erros na palavra formada, as letras posicionadas corretamente são mantidas e as incorretas são retiradas para os estudantes organizarem novamente. Embora possua essa qualidade, entende-se que o aplicativo Forma Palavras não é adequado para este nível de leitura e escrita, pois não possui áudio das instruções de jogo, do nome das imagens ou dos sons das sílabas.

Portanto, para o segundo nível de leitura e escrita somente o aplicativo Lele das Sillabas foi considerado parcialmente adequado. Os aplicativos Alfabetizando e Forma Palavras não foram considerados apropriados, pois não possuem os requisitos básicos, isto é, rimas, associação de palavras a imagens, separação de sílabas, enunciado em áudio e áudios claros e pausados, que são importantes para o nível silábico.

\section{Nível silábico-alfabético}

Para o nível silábico-alfabético, os aplicativos são o Silabando, Monta Palavras e Gamefono. O Silabando tem como principal foco a aprendizagem das sílabas simples e 
http://dx.doi.org/10.5902/1984686X46925

complexas, pois apresenta a montagem de sílabas e ilustração; a opção de completar a palavra com a sílaba correspondente; escutar a sílaba e tentar descobrir qual é a adequada; com a palavra separada em sílabas, descobrir a imagem correta; e descobrir o número de sílaba que cada palavra tem. Este aplicativo foi considerado pelos três estudantes como bastante atrativo e lúdico. Além do mais, possui diversas opções de jogos que favorecem a aprendizagem de leitura e da escrita de forma espontânea. Petry $(2016$, p.45) reafirma esta questão, segundo ele, "por meio de jogos, a criança realiza com vontade aquilo que não gostaria de realizar se fosse forçada". A presença de instruções com áudio favoreceu a compreensão e a autonomia durante a utilização. Os áudios nas imagens e palavras e sílabas nas opções do jogo proporcionaram aos três estudantes aprimorar as suas habilidades de leitura e escrita.

Para Passerino; Dias e Rapkiewicz (2010), a implementação e inclusão de áudio para todos os campos do objeto de aprendizagem é um ajuste que pode tornar o objeto acessível de forma simples. Ainda segundo os autores, os objetos com acessibilidade não beneficiam só as pessoas com algum tipo de deficiência, pois podem ser explorados por outros públicos e, de forma também eficaz, contribuir com seu processo de aprendizagem.

O aplicativo tem a opção de, primeiramente, trabalhar a formação das silabas ou a retomada das famílias silábicas. Nesta opção, os estudantes puderam rever como são formadas algumas sílabas. É uma opção de revisão, tanto das sílabas simples, como das complexas, bastante didática para este nível de leitura e de escrita, pois são expressos os sons das letras e o som formado com a união destas. Isto torna-se interessante, pois conforme Ferreiro e Teberosky (1986), neste nível, os estudantes ainda escrevem omitindo algumas letras das sílabas ou usam apenas uma letra para representá-las.

$\mathrm{Na}$ opção de jogo, na qual os estudantes devem clicar na sílaba que falta para completar a palavra, foi possível perceber que nenhum estudante teve dificuldade de compreender, já que o jogo possui instrução em áudio clara e objetiva e, além disso, possui áudio em todas as sílabas e imagens. Para Busarello (2016), o estudante sente-se envolvido com a atividade quando entende o que deve ser realizado. O layout também foi destacado pelo estudante $\mathrm{A} 8$, por ser colorido e com desenhos grandes. "O caráter da novidade, o dinamismo e o ambiente diferenciado é que promoveram um clima de motivação entre os alunos" (HENRIQUE; SOUZA; SILVA, 2010, p. 79).

A última opção consiste em descobrir o número de sílabas da palavra dada. Nesta opção, apesar do áudio com instruções claras, A6 teve dificuldade em realizar a contagem 
http://dx.doi.org/10.5902/1984686X46925

das sílabas, mas, após refazer a tarefa algumas vezes, compreendeu como contar o número de sílabas. Segundo Busarello (2016, p.32), este fato de refazer a tarefa "é um motivador para uma busca constante de melhorias e de maneiras novas para encontrar soluções".

Todas as opções de jogo do aplicativo Silabando possuem feedback positivo e negativo. Isto "serve para fornecer dados ao jogador, informando-o onde se encontra no ambiente e o resultado de suas ações" (BUSARELLO, 2016, p.111). Além disso, possui os sons de todas as sílabas, palavras e imagens presentes nas opções de jogo do aplicativo. Assim, pode-se constatar que este aplicativo "possui uma proposta bem estruturada em que o objeto de aprendizagem é elemento mediador, que pode ser promovedora de desenvolvimento e aprendizagem" (HENRIQUE; SOUZA; SILVA, 2010, p.66).

O aplicativo Monta palavras tem como objetivo identificar as sílabas e ordená-las formando a palavra corretamente. Tem três níveis diferentes de dificuldade: fácil (com palavras dissílabas), normal (trissílabas) e difícil (polissílabas). Estes diferentes níveis de dificuldade contemplaram uma das propostas pedagógicas para o nível silábico-alfabético, visto que proporcionaram aos estudantes formar palavras com uma complexidade gradativa, com diferentes números de sílabas. Para Busarello (2016, p.77), "estruturar níveis de dificuldades progressiva, permite ao sujeito se familiarizar com o ambiente e com as regras, desenvolvendo habilidades em tarefas complexas".

No entanto, inicialmente, os três estudantes não compreenderam qual o intuito do jogo, visto que não possui enunciado escrito ou em áudio. Ademais, o aplicativo não possui feedback e áudio com os sons das sílabas e nomes das imagens. Isso dificultou as construções de algumas palavras, pois os estudantes desconheciam algumas imagens, como, por exemplo, maçarico. Busarello (2016, p.81) chama atenção a esse aspecto, "em jogos digitais educativos, é especialmente importante considerar aspectos relacionados ao contexto para o qual o jogo é desenvolvido".

Outro fator que dificultou a formação das palavras por parte dos estudantes foi as imagens e as sílabas possuírem um tamanho pequeno, não permitindo o reconhecimento de algumas, deixando-os desmotivados. A motivação é necessária para garantir a aprendizagem e para avaliar um programa educativo, pois aumenta a efetividade da atividade. Desse modo, o aplicativo Monta palavras não é adequado para este nível de leitura e escrita, pois não contempla alguns requisitos importantes, como, exemplo, a presença de feedbacks e de áudios no enunciado, nas sílabas e nas imagens. 
http://dx.doi.org/10.5902/1984686X46925

Gamefono também trabalha com a formação de palavras. Na primeira opção, devese escolher as sílabas que formam o nome da imagem dada, a outra opção consiste em clicar na palavra correspondente à imagem. $\mathrm{O}$ aplicativo tem recursos visuais grandes $\mathrm{e}$ atrativos e áudio claro do nome de cada imagem, mas não possui os sons das sílabas na opção para formar as palavras. Igualmente, os enunciados são somente escritos e aparecem rapidamente em letras pequenas, o que não proporcionou aos três estudantes compreenderem sozinhos as instruções do aplicativo.

O fato de todas as escritas serem em letra bastão favoreceu a construção e a leitura das palavras solicitadas, pois trata-se de uma situação de aprendizagem dentro do contexto dos sujeitos da pesquisa, visto que este sujeito somente costuma trabalhar com propostas com este tipo de letra. Conforme Tobias; Fletcher e Wind (2014), quanto mais a situação tratada no jogo for parecida com aquelas que se deseja como alvo de aprendizagem, mais provável será a transferência de aprendizagem. Apesar de possuir essa qualidade, entende-se que o aplicativo Gamefono não é adequado, pois não apresenta um requisito muito importante para este nível de leitura e escrita, o som nas sílabas.

Portanto, para o terceiro nível de leitura e escrita, o aplicativo Silabando é o que mais apresenta potencial de uso, visto que contempla a maioria dos aspectos pedagógicos e técnicos necessários para esse nível. Os aplicativos Monta palavras e Gamefono, por não possuírem os requisitos de enunciados em áudios e escritos, completar textos com palavras, contar número de sílabas e letras, completar palavras com sílabas complexas, os quais são entendidos como básicos para o nível silábico-alfabético, não foram considerados adequados.

\section{Nível alfabético}

Para o nível alfabético, os aplicativos são $A B C$ português, Caça palavras e Palavras Guru. $\mathrm{O}$ aplicativo $A B C$ português possui seis opções de utilização e, inicialmente, o usuário deve escolher a temática das palavras. As opções de utilização do aplicativo são: glossário de palavras e áudios; relacionar áudio com a grafia; relacionar escrita com a imagem; formar a palavra de acordo com o áudio; associar palavra e imagem e associar áudio a imagem.

O aplicativo destacou-se perante os três sujeitos pela diversidade de opções de jogos, layout atrativo e colorido e a presença de temas variados. Estes fatos chamaram atenção e fizeram com que os participantes demonstrassem bastante interesse. A motivação é necessária para "garantir a aprendizagem e para avaliar um programa educativo" 
(BUSARELLO, 2016, p. 63). A presença do glossário de palavras e os áudios fizeram com que os três sujeitos ampliassem seus vocabulários e facilitaram sua desenvoltura nas opções de jogos, pois os alunos tinham conhecimento das imagens e palavras apresentadas. Este fato revela que "o potencial educativo dos jogos está em como eles motivam e promovem a aprendizagem" (BAHIA, 2016, p.80).

Os jogos possuem feedback negativos (áudio) e, quando está correta a palavra, o feedback positivo é realizado através do áudio da palavra tratada no momento. Os três sujeitos apresentaram dificuldade quando cometeram erros, principalmente na opção de formar a palavra, pois somente foi dado um aviso sonoro de erro, mas as letras erradas não foram eliminadas das palavras, o que causou dificuldades para os três sujeitos, pois, como as letras permaneciam, eles tiveram dúvidas. Mesmo apresentando essa falha, o aplicativo $A B C$ português é adequado, pois possui muitas características condizentes com as necessidades deste nível de leitura escrita.

O segundo aplicativo, o Caça-palavras, tem três níveis de dificuldade: fácil, normal e difícil e possui dez opções de temas de palavras. Consiste em procurar e encontrar todas as palavras escondidas na grade. Os sujeitos não encontraram dificuldade em compreender o propósito do aplicativo, mesmo não possuindo instruções escritas ou em áudios, pois já eram familiarizados com este tipo de jogo. A atividade proposta no aplicativo é interessante, mas não gerou motivação e não foi desafiadora para os participantes. Uma dificuldade apresentada pelos três sujeitos foi que algumas palavras estavam, no caça-palavras, escritas de trás para frente e na diagonal.

Para cada um dos três níveis de dificuldade, há uma quantidade diferente de palavras, que possuem um nível de complexidade também diferente. A opção pela temática das palavras possibilitou aos sujeitos escolherem o tema em que as palavras fossem do seu contexto, o que facilitou a leitura e seu reconhecimento. $O$ aplicativo não possui feedback positivo e negativo, quando as palavras são encontradas corretamente é possível grifá-las, selecionando todas as letras que as compõem. Automaticamente, quando grifada, a palavra é riscada do banco de palavras a ser buscada. Embora o aplicativo não apresente feedback e não tenha motivado suficientemente os alunos, pode-se concluir que aplicativo caçapalavras é adequado, pois apresenta os requisitos de letra bastão ou de imprensa ou cursiva, enunciados escritos, localização de palavras ou frases, que são minimamente necessários para este nível de leitura e escrita. 
O último aplicativo deste nível, Palavras Guru, tem como intuito montar as palavras a partir das letras dadas e ampliar o vocabulário do usuário. Os três sujeitos tiveram dificuldade de arrastar as letras e formar as palavras, não conseguindo passar da primeira fase do jogo. O jogo possui feedback positivo, os sujeitos ganham moedas como forma de prêmio e o feedback negativo consiste em um aviso sonoro. Mesmo possuindo um recurso importante, como o feedback, o aplicativo Palavras Guru não se mostrou adequado a este nível de leitura e escrita, pois não possui características apropriadas ao nível alfabético.

Portanto, para o quarto nível de leitura e escrita, os aplicativos $A B C$ português e Caçapalavras são os mais adequados e o aplicativo Palavras Guru, apesar de ser muito criativo e interessante, não possui as características necessárias para o nível alfabético.

\section{Análise dos aplicativos e a relação com a deficiência intelectual}

Com base na discussão dos resultados, que teve por objetivo analisar o potencial dos aplicativos educacionais no ensino da leitura e escrita com alunos com deficiência intelectual, foram realizadas algumas constatações.

No nível pré-silábico, dos três aplicativos utilizados, $A B C$ for Kids e Alphabet apresentam potencial para o desenvolvimento da leitura e escrita, o terceiro, possui poucos recursos que contemplam o nível e necessita de mediação para ser utilizado pelo aluno. Os aspectos pedagógicos que não estavam presentes foram separar e/ou marcar as letras ou os números; imagem com a escrita do nome e associação a letra inicial; ordem alfabética; motivação; parear nomes ou desenhos ou letras iguais; e ludicidade e os aspectos técnicos estavam todos presentes. Levando-se em consideração o aluno com DI, verifica-se que o terceiro aplicativo não é adequado para estes sujeitos, neste nível de leitura e escrita, visto que não contempla a maioria dos aspectos pedagógicos. Assim, devido às dificuldades cognitivas da deficiência intelectual, este aplicativo não proporcionaria ganhos pedagógicos a estes sujeitos.

No segundo nível, o silábico, apenas Lele das sílabas apresentou potencial parcialmente adequado. Os outros dois aplicativos analisados não contemplaram os requisitos básicos, rimas, associação de palavras a imagens, separação de sílabas, enunciado em áudio e áudios claros e pausados, que são importantes para o nível em questão. Considerando que os sujeitos da pesquisa são alunos com DI, os aspectos pedagógicos: rimar associar palavra a imagem; separar de sílabas; e associar sons inicial/final à imagem, e os aspectos técnicos: enunciados em áudio e feedback que não 
http://dx.doi.org/10.5902/1984686X46925

estão presentes nos aplicativos, dificultam estes sujeitos a construção desta hipótese de leitura escrita. A presença dos sons das letras e sílabas são um dos aspectos indispensáveis na construção desta hipótese de leitura e escrita para o sujeito com DI neste nível.

Para o terceiro nível de leitura e escrita, o silábico-alfabético, dos três aplicativos selecionados, o Silabando apresentou maior potencial de uso visto que contempla a maioria dos aspectos pedagógicos e técnicos necessários para esse nível. Os outros dois aplicativos, Monta Palavras e Game Fono, por não possuírem alguns aspectos pedagógicos, como completar textos com palavras; completar palavras com sílabas complexas; e contar o número de sílabas e de letras e aspectos técnicos, como letra bastão; enunciados em áudio e escrito e feedback não foram considerados adequados. A ausência desses itens, nos aspectos pedagógicos e técnicos, não proporcionou um ensino/aprendizagem de qualidade, pois o aluno com DI necessita que as informações sejam totalmente claras, objetivas e, de preferência, de acordo com o contexto no qual estão inseridos. Estes sujeitos, diferentemente dos sujeitos sem deficiência intelectual, podem apresentar dificuldades cognitivas que fazem com que eles possuam uma aprendizagem em um ritmo diferente e com necessidades específicas de explicações, motivações, incentivos e contextualizações diferenciadas.

No quarto nível de leitura e escrita, o alfabético, $A B C$ português e Caça palavras contemplam uma grande parte dos aspectos técnicos e pedagógicos. A presença de letra bastão, imprensa ou cursiva e localização de palavras ou frases é fundamental para o desenvolvimento da aprendizagem de alunos com DI. O terceiro aplicativo, apesar de ser muito criativo e interessante, não possui as características necessárias paras o nível alfabético. A presença de aspectos pedagógicos, como leituras diversas e aspectos técnicos, como feedback, mostram-se insuficientes, quando o usuário deste nível de leitura e escrita apresenta deficiência intelectual e a presença dos demais aspectos técnicos e pedagógicos são indispensáveis a estes sujeitos.

Ressalta-se novamente que, apesar dos sujeitos com deficiência intelectual percorrerem os mesmos níveis de leitura e escrita, descritos por Ferreiro e Teberosky (1986), eles possuem peculiaridades pedagógicas neste percurso de aprendizagem. Os sujeitos com DI, em decorrência de suas características cognitivas próprias, necessitam que as instruções das propostas pedagógicas, para cada nível de leitura e escrita, sejam bastante claras e objetivas para que ocorra a compreensão do que está sendo proposto. 
Além disso, a ludicidade também é outro fator de extrema importância para estes sujeitos, visto que muitos apresentam, além das dificuldades de aprendizagem das habilidades, resistência em realizar estas propostas. Desse modo, o lúdico contribui significativamente para o envolvimento e motivação destes sujeitos no ensino/aprendizagem das habilidades de leitura e escrita. $\mathrm{O}$ incentivo positivo (feedback positivo) também é um fator motivador para estes sujeitos e o feedback negativo é igualmente importante, pois deve ser uma maneira de transformar o erro em aprendizagem. Diante disso, o feedback deve ser realizado de uma maneira que proporcione ao sujeito com deficiência intelectual, compreender o motivo do seu erro de uma maneira bem simples.

Portanto, constatou-se que para que os aplicativos contemplem os requisitos mínimos necessários para potencializar cada nível de leitura e escrita, proposto por Ferreiro e Teberoski (1986), devem ser observados aspectos pedagógicos e técnicos, sobretudo com estudantes com deficiência intelectual.

\section{Conclusão}

Os movimentos e políticas em prol da educação inclusiva aliados ao desenvolvimento tecnológico promoveram mudanças significativas na utilização de recursos e estratégias pedagógicas, nas salas de aula regular e nos espaços de atendimento ao público alvo da educação especial, o AEE. As tecnologias móveis oferecem uma variedade de aplicativos que visam atender às demandas da sociedade e, por conseguinte, oferecem múltiplas possibilidades aos professores para potencializar o ensino e a aprendizagem de todos os alunos, no sentido de prepará-los para conviver em sociedade de modo mais igualitário. As habilidades de leitura e escrita são essenciais nesse processo, pois permitem que o sujeito sinta-se inserido nesse contexto.

Considerando os estudantes com deficiência intelectual, sujeitos dessa pesquisa, 0 uso de aplicativos que auxiliem no desenvolvimento dessas habilidades, aparece como um recurso potencializador capaz de atender às necessidades individuais, de acordo com o nível de leitura e escrita em que está cada sujeito, respondendo assim, ao objetivo da pesquisa.

Nesse sentido, ao finalizar este estudo, é possível tecer algumas considerações: a importância da Matriz de Referência, que apresenta quais os requisitos necessários que 0 estudante deve ter em cada nível de leitura e escrita e, indica os aspectos pedagógicos e 
técnicos que os aplicativos devem conter, em cada um desses níveis, foi fundamental para verificar o potencial dos aplicativos. A diferença existente entre os aplicativos que versam a mesma temática, sendo alguns mais elaborados, outros menos, faz com que alguns sejam mais adequados ao processo de ensino e de aprendizagem. Ademais, a inexistência de aplicativos sobre leitura e escrita, pensados especificamente para o público que possui deficiência intelectual, fato que se justifica em razão desses sujeitos possuírem diferentes níveis de desenvolvimento.

Sendo assim, a pesquisa apresenta perspectivas futuras com o desenvolvimento de diretrizes para a criação e utilização de aplicativos baseados nos quatro níveis de leitura e escrita. Assim, beneficiaria não só os sujeitos com deficiência intelectual, mas todos os outros sujeitos nestes níveis. Portanto, a contribuição do estudo intenciona alavancar mais pesquisas que contemplem os aplicativos, os níveis de leitura e de escrita e o AEE, a fim de contribuir com a educação do público desta modalidade.

\section{Referências}

ANDRADE, Maria Margarida de. Técnicas para elaboração dos trabalhos de graduação. In: Introdução à metodologia do trabalho científico. 7. ed. São Paulo: Atlas, 2006, p. 25-38.

BAHIA, Ana Beatriz. Desenhando health games para não gamers. In: ALVES, Lynn e COUTINHO, Isa de Jesus. Jogos Digitais e aprendizagem: fundamentos para uma prática baseada em evidências. Campinas: Papirus, 2016, p. 77-104.

BRASIL. Política Nacional de Educação Especial na Perspectiva da Educação Inclusiva. Brasília: MEC/SEESP, 2008.

BRASIL. Declaração de Salamanca e linha de ação sobre necessidades educativas especiais. Brasília: CORDE, 1994.

BUSARELLO, Raul Inácio. Gamification: princípios e estratégias. São Paulo: Pimenta Cultural, 2016. 140p.

ESPINOSA, Ruth Contreras. e GÓMEZ, Jose Luis Eguia. Pesquisa da avaliação e da eficácia de aprendizagem baseada em jogos digitais: reflexões em torno da literatura científica. Trad. Beatriz Marchesini. In: ALVES, Lynn e COUTINHO, Isa de Jesus. Jogos digitais e aprendizagem: fundamentos para uma prática baseada em evidências. Campinas: Papirus, 2016, p. 61-76.

FAGUNDES, Natalia Filipini. O uso de aplicativo de celular como recurso didático no Atendimento Educacional Especializado (AEE) com aluno autista do ensino fundamental. Artigo (especialização) - Universidade Federal de Santa Maria, Centro de Tecnologia, Curso de Especialização em Mídias na Educação, EaD, RS, 2019. 
FERREIRO, Emilia; TEBEROSKY, Ana. A psicogênese da língua escrita. Diana Myriam Lichteinstein (Trad.). Porto Alegre: Artes Médicas, 1986.

GALVÃO FILHO, Teófilo. Tecnologia Assistiva: favorecendo o desenvolvimento e a aprendizagem em contextos educacionais inclusivos. In: GIROTO, Claudia Regina Mosca; POKER, Rosimar Bortolini. OMOTE, Sadão. (Org.). As tecnologias nas práticas pedagógicas inclusivas. Marília/SP: Cultura Acadêmica, 2012 p. 65-92.

GALVÃO FILHO, Teófilo. Deficiência intelectual e tecnologias no contexto da escola inclusiva. In: GOMES, Cristina (org.). Discriminação e racismo nas Américas: um problema de justiça, equidade e direitos humanos. Curitiba: CRV, 2016, p. 305-321. Disponível em: http://www.galvaofilho.net/DI_tecnologias.htm. Acesso em: 11 jul. 2020.

GIL, Antonio Carlos. Como elaborar projetos de pesquisa. 5. ed. São Paulo: Atlas, 2010.

HENRIQUE, Hélen Cristina Rodrigues; SOUZA, Fúlvio Rafael Bento de; SILVA, Rejane Maria Ghisolfi. Avaliando mediações e interações "com, no e pelos" objetos de aprendizagem no contexto escolar. In: SOUZA JUNIOR, Arlindo José. et al. Objetos de aprendizagem: aspectos conceituais, empíricos e metodológicos. Uberlândia: Edufu, 2010, p. 61-98.

MANTOAN, Maria Teresa Eglér; BATISTA, Cristina Abranches Mota. Atendimento educacional especializado em deficiência mental. In: BRASIL. Atendimento educacional especializado: deficiência mental. Brasília: SEESP/MEC, 2007, p. 13-42.

MINAYO, Maria Cecília de Souza. $O$ desafio do conhecimento, pesquisa qualitativa em saúde. São Paulo/ Rio de Janeiro: Hucitec/ABRASCO, 2014.

MOOJEN, Sônia Maria Palaoro. A escrita ortográfica na escola e na clínica - teoria, avaliação e tratamento. São Paulo: Casa do Psicólogo, 2009.

ORGANIZAÇÃO DAS NAÇÕES UNIDAS PARA A EDUCAÇÃO E A CULTURA. Relatório Global UNESCO - abrindo novos caminhos para o empoderamento: TIC no acesso à informação e ao conhecimento para as pessoas com deficiência /UNESCO. São Paulo: Comitê Gestor da Internet no Brasil, 2014.

PAIXAO, Katia de Moura Graça. Mediação Pedagógica e Deficiência Intelectual: em cena a linguagem escrita. Tese de Doutorado. Universidade Estadual Paulista Júlio de Mesquita Filho. Marília, 2018.

PASSERINO, Liliana Maria.; DIAS, Carla Cristina Lui E RAPKIEWICZ, Clevi Elena. Acessibilidade em Objeto de Aprendizagem na Área de Química: uma mistura legal. In: Arlindo José de Souza Junior; Carlos Roberto Lopes; Márcia Aparecida Fernandes; Rejane Maria Ghisolfi da Silva. (Org.). Objeto de aprendizagem: aspectos conceituais, empíricos e metodológicos. 124 ed. Uberlândia: EDUFU, 2010. 
PETRY, Arlete dos Santos. Jogos digitais e aprendizagem: algumas evidências de pesquisa. In: ALVES, Lynn; COUTINHO, Isa. Jogos digitais e aprendizagem: fundamentos para uma prática baseada em evidências. Campinas: Papirus, 2016, p. 4360.

ROCHA, Jaquelini Grillo Biral, \& THIENGO, Edmar Reis. Alfabetização de estudante com deficiência intelectual: uso de um software educativo. Revista Eletrônica Acervo Saúde, 11(11), e513, 2019. Disponível em: https://doi.org/10.25248/reas.e513.2019 Acesso em: 22 ag. 2020.

RODRIGUES, Jeanine Taís Drescher. As tecnologias da informação e da comunicação na mediação da alfabetização de alunos com deficiência intelectual. Artigo (especialização) - Universidade Federal de Santa Maria, Santa Maria, 2018. Disponível em: http://repositorio.ufsm.br/handle/1/15368. Acesso em: 9 jul. 2020.

SANTOS, Maria Aline Marques dos. Promoção da aprendizagem da leitura através das Tecnologias da Informação e Comunicação, numa criança com Perturbação do Espetro do Autismo. Dissertação de Mestrado. Escola Superior de Educação, Instituto Politécnico de Coimbra. Coimbra, 2014.

TOBIAS, Sigmund; FLETCHER, Dexter; WIND, Alexander. Game based learning. In: SPECTOR, J.M. et al. (org). Editors handbook of research on educational communications and techbology. 4aㅡ ed. Nova York: Springer Science +Business Media, 2014.

\section{Correspondência}

Ana Cláudia Oliveira Pavão - Universidade Federal de Santa Maria, Departamento de Educação Especial, Centro de Educação, Av. Roraima, n.1000, Camobi, Santa Maria, Rio Grande do Sul - Brasil.

CEP: $97105-900$

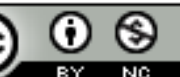

This work is licensed under a Creative Commons Attribution-NonCommercial 4.0 International (CC BY-NC 4.0) 